\title{
DEVELOPMENT OF DIABETES MELLITUS IN HYPOPITUITARISM
}

\author{
By S. S. JHAVERI, M.D., M.R.C.P.E. \\ Late Senior House Officer, Victoria Hospital, Accrington (Lancs); \\ now Medical Registrar, Burnley Group of Hospitals, Burnley
}

The importance of the anterior pituitary in diabetes mellitus was first demonstrated in 1931 by Houssay and Biasotti, when they showed that the post-pancreatectomy diabetes in experimental dogs could be alleviated by removing the anterior pituitary. It was also observed that if pituitary extracts were injected in the 'Houssay Dog,' the diabetes reverted to its former severity. Later, Young (r937) found that prolonged administration of anterior pituitary extracts into the adult dogs led to the development of diabetes mellitus. The occurrence of hyperglycaemia and glycosuria in many acromegalics had been recognized for many years.

The role of the pituitary and other endocrine glands in the etiology of diabetes mellitus has been much stressed during the past two decades. Himsworth (1949) stated that diabetes can no longer be considered as a single entity but a syndrome. However, there are many questions not yet completely solved or explained, such as the complications of the disease process.

The Houssay phenomena first described in the experimental dogs has been reported in man on various occasions due to diverse lesions of the anterior pituitary. It is extremely rare, however, for the sequence of events to be reversed and I have been able to find only two previous reports of such a condition.

\section{Case Report}

Miss E. G., aged 39, was referred in October 1952 by her doctor to the surgical out-patients for complaint of abdominal pain. For several years she had suffered from intermittent epigastric pain, heartburn, and vomiting. Pain had no relation to food. Barium-meal examination then revealed persistent irregularity in the lesser curve fornix of duodenal cap with a small ulcer crater. She was treated with gastric diet, antacids and sedatives. Later her symptoms worsened and she was admitted to the surgical ward with a presumptive diagnosis of pyloric stenosis. She was then found to have congenital heart lesion which, according to her statement, had been detected in infancy. She had always tired easily and was short of breath. She also complained of occasional ' black-outs,' attacks of palpitations and substernal pains and had had winter coughs for many years. A right mastoidectomy had been performed in 1949. Intermittent discharge, pain and partial deafness had persisted since the operation. She had erysipelas in 1935 and repair of right inguinal hernia at Manchester Royal Infirmary in 1945. Bariummeal examination while in the hospital showed 30 per cent. six-hour gastric residue, but the stomach was empty at 24 hours. The duodenaf cap still showed the small ulcer crater at the base? Fractional test meal revealed hyperacidity. She was discharged from the hospital after two weeks. She was later readmitted in March 1954 for haemorrhoidectomy. In September 1954 she was referred to E.N.T. specialist for severe pain in right ear. His opinion was that he could not find any organic cause for her recent pain, which appeared more to be functional in origin. The psychiatrist thought that she was a pathetic little woman who had been brought up in an excessively protective environment, was too much sheltered from the world at large, which had produced a chronic neurotic personality with gross inadequacy and hysteriform trends. She was admitted to the surgical ward in November 1955 for acute exacerbations of her peptic ulcer symptoms. The results of barium-meal examination and fractional test meal were essentially the same as before.

In August $195^{6}$ she was referred to the medical out-patients for thirst, polyuria, tiredness, lack of energy, and loss of weight. Glucose tolerance test after $50 \mathrm{~g}$. of oral glucose revealed mild diabetes. She was well on a ro lines diet (Lawrence ' LineRation scheme '). She was admitted to the medical ward in July 1957 as diabetic precoma. Though her doctor did notice ketonuria, there was no acetone in her urine on admission. On examination, she was a dwarf and had a high-grade myopia; 


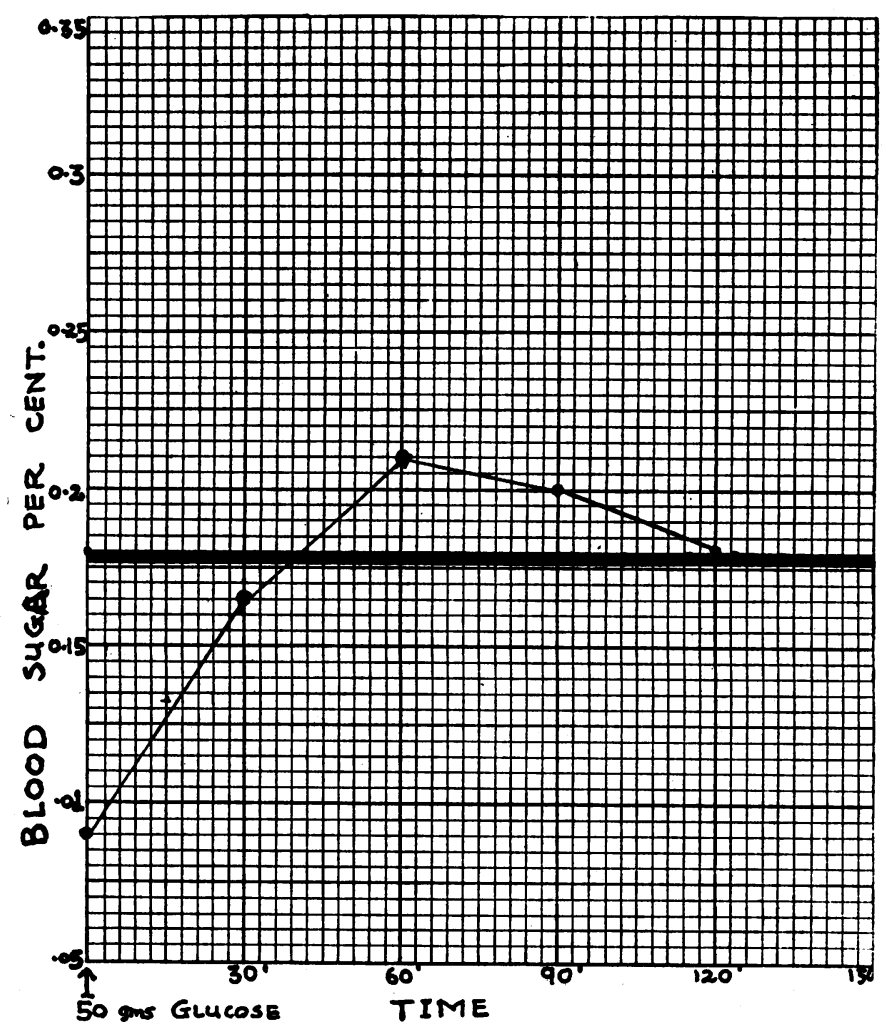

weight 72 lb.; height 52 in.; span 50 in.; vertex of symphysis pubis 26 in.; symphysis to sole 26 in.; she had no arachnodactyly. Skin was warm and dry. There were a few sparse hairs at pubis but none in axillae. Her menstrual periods were scanty but fairly regular, and accompanied with moderate pain. There was mild deformity of right chest and depressed sternum. Examination of the heart revealed visible and palpable apex beat in $5^{\text {th }}$ left intercostal space, $4 \frac{1}{2}$ in. away from the mid-sternal line, slapping in character. There was right ventricular heave and systolic thrill at base. At apex first sound was loud and muffled and at base masked by a grade IV murmur, radiating towards left clavicle. Second sound was heard at apex but was absent at base. There was no diastolic murmur. Pulse was 92 per minute with occasional premature beat. B.P. $120 / 70 \mathrm{~mm}$. $\mathrm{Hg}$. Fundi showed chorio-retinal atrophy more than that can be accounted by usual myopic changes and presence of incipient cataract in both eyes.

\section{Investigations}

Urine showed sugar ++ but no albumin; R.B.C. 5 million per c.mm.; Hgb. Ioo per cent. white cells 8,600 per c.mm. with normal differen- tial; total serum proteins $6.2 \mathrm{~g}$. per cent., albumin 4.2 g. per cent., globulin 2 g. per cent. Serum cholesterol $174 \mathrm{mg}$. per cent.; B.M.R. plus ro per cent.; 24 hours 17 ketosteroid excretion was $4.4 \mathrm{mg}$. (normal value for female, 5 to $12 \mathrm{mg}$. per 24 hours); 24 hours urinary gonadotropins, 4 units (normal value, 5 to 25 units); X-ray chestthe transverse diameter of the heart was within normal limits but there was definite fullness of the pulmonary conus. The lungs appeared to be normal; on screening there was fullness of pulmonary conus but no pulsation could be seen. There was no enlargement of left auricle or left ventricle. X-ray skull-the pituitary fossa was extremely small. No other abnormality noted. $\mathrm{X}$-ray spine-and pelvis-normal: the epiphysis of the femora were united with shafts; E.C.G. showed right-ventricular hypertrophy and strain pattern with occasional premature beats.

She was considered to be a case of hypopituitarism chiefly affecting the gonads. The following regime was begun on October 28, 1957: (a) dry thyroid extract, $\frac{1}{2}$ gr. twice daily; $(b)$ cortisone, 12.5 mg. twice daily; and ro lines diet was continued. She was followed up periodically in the out-patients' department. There were no complaints and some subjective improvement was 
noticed for five weeks. Then she started vomiting and lost her appetite. She also complained of severe constipation. Regular testing of three daily specimens of urine by herself and periodic check-up at the hospital showed no material difference in her diabetic state. Her general physical and mental condition were almost the same.

\section{Discussion}

The history of the patient is suggestive that hypopituitarism has been probably present since childhood. The diabetes developed in the circumstances which would appear antagonistic to it. The Houssay phenomenon in man has been recorded with its chief effects being, as would be expected, marked increase in sensitivity to both endogenous and exogenous insulin. It is thus surprising to find that diabetes mellitus in its true form may occur in an unusual person who shows clear evidence of pituitary hypofunction over a period of three months.

The therapeutic use of cortisone and thyroid did not materially change her physical and mental outlook. The axillary hair did not appear, nor had there been any increase in pubic hair. The breasts did not increase in size and, though there was slight increase in the menstrual flow, libido was absent. The diabetic state, as judged by urine examination, did not react to hormone in expected fashion.

\section{Summary}

A case of hypopituitarism with congenital pulmonary stenosis is reported in which diabetes mellitus developed after many years of deficient pituitary function. The clinical findings, laboratory investigations, and follow-up observations are described, with special reference to diabetic state which did not alter under the mentioned hormones.

\section{Acknowledgment}

I express my sincere thanks to Dr. A. L. McAdam, the consulting physician, for his helpful criticism and for allowing me to publish the case report; to Dr. W. B. Waring, house physician, for his help; to Mr. Walsh and his staff of the $\mathrm{X}$-ray department; and to Miss $\mathrm{M}$. Crabtree for her secretarial help.

\section{BIBLIOGRAPHY}

GRUNBERG, A., and BLAIR, J. L. (1957), Brit. med. F., ii, 439 HIMSWORTH, H. P. (1949), Lancet, i, 465.

HOUSSAY, B. A., and BIASOTTI, A. (1931), Endocrinology, r5, 5 II.

SHEEHAN, H. L., and SUMMERS, V. K. (1949), Quart. F. Med., 18, 319.

YOUNG, F. G. (1937), Lancet, ii, 372.

\title{
CARCINOMA OF THE BRONCHUS
}

\author{
Price 5s. 6d. post free
}

\section{INTRODUCTORY}

Maurice Davidson, D.M., F.R.C.P.

THE INCIDENCE AND AETIOLOGY OF PRIMARY CARCINOMA OF THE LUNG

C. E. Drew, M.V.O., F.R.C.S.

\section{MEDICAL ASPECTS}

J. Anderson, M.D., F.R.C.P.

RADIOLOGICAL ASPECTS

G. Simon, M.D., D.M.R.E., F.F.R.
UNUSUAL MANIFESTATIONS

J. Smart, M.D., F.R.C.P.

CYTOLOGICAL EXAMINATION OF THE SPUTUM AND PLEURAL EFFUSION

J. L. Pinniger, D.M., M.R.C.P.

THE SCOPE OF RADIOTHERAPY

Gwen Hilton, D.M.R.E., F.F.R.

SURGERY OF CARCINOMA OF THE BRONCHUS

L. L. Bromley, M.Chir., F.R.C.S

Published by

THE FELLOWSHIP OF POSTGRADUATE MEDICINE

60, Portland Place, London, W.1 